\title{
Morbus Wilson - das Wichtigste ist: „daran zu denken“
}

Ulrike Reuner, Jürgen Dinger

\author{
Der Morbus Wilson ist eine seltene Erkrankung - frühzeitig erkannt und behandelt \\ ist die Prognose günstig. Symptomfreiheit und normale Lebenserwartung sind \\ realistische Therapieziele. Setzt die Behandlung zu spät ein, verbleiben oft Funk- \\ tionsstörungen, auch in alltagsrelevantem Ausmaß. Unbehandelt verläuft die \\ Erkrankung tödlich. Als „Chamäleonerkrankung“ ist der Morbus Wilson eine \\ wichtige Differenzialdiagnose in vielen Fachbereichen.
}

\section{Definition, Historisches, Epidemiologie}

Der Morbus Wilson (Synonyme: hepatolentikuläre Degeneration, Pseudosklerose Westphal) ist eine seltene (ORPHA-Kennnummer 905) autosomal-rezessiv vererbte Störung des hepatischen Kupferstoffwechsels, die zu einer verminderten biliären Kupferausscheidung über die Galle und zu einem verminderten Einbau von Kupfer in Apocoeruloplasmin führt [1]. Die Akkumulation von Kupfer in der Leber mündet schließlich in einer Überladung der Hepatozyten und deren Zerstörung durch verschiedene toxische Mechanismen (u.a. mitochondriale und lysosomale Toxizität), die freies Kupfer infolge Radikalbildung bewirkt.

Es resultieren Leberfunktionsstörungen bis hin zur Leberinsuffizienz und damit einhergehend die Freisetzung und Umverteilung des freien (toxischen) Kupfers ins Blut und andere Organsysteme, insbesondere ins Gehirn und die Kornea (Kayser-Fleischer-Kornealring).

Die populationsabhängige und auf klinischen Daten beruhende geschätzte Prävalenz beträgt weltweit ca. 1:30000. Unter Berücksichtigung von Sequenzierungsdaten des gesamten ATP7B-Gens ist sie vermutlich wesentlich höher (1:7026). Die Inzidenz beträgt 15-30 auf 1 Million. Bei einer angenommenen Genfrequenz von $0,3-0,7 \%$ liegt die geschätzte Häufigkeit für heterozygote Anlageträger zwischen 1:90 und 1:180.

Aufgrund des autosomal-rezessiven Erbgangs ergibt sich für Geschwister einer erkrankten Person ein statistisches Risiko von 1:4, ebenfalls betroffen zu sein, für Kinder einer erkrankten Person von 1:200. Ein Familienscreening ist bei Diagnosestellung zwingend geboten [1]. Männer und Frauen sind gleich häufig betroffen.

\section{Pathogenese}

Ursächlich für die Manifestation der Erkrankung sind homozygot oder compound heterozygot auftretende Mutationen im sog. Wilson-Gen (ATPase 7B-Gen, Wilson's Disease Gene, lokalisiert auf dem langen Arm des Chromosoms 13 3q14-21). Bislang wurden weltweit mehr als 500 Mutationen, verteilt über 21 Exone, identifiziert, die je nach Ethnie unterschiedlich häufig auftreten. In Mitteleuropa ist die Punktmutation C3207A im Exon 14, mit Aminosäureaustausch His1069Q, die mit etwa 50-80\% häufigste Mutation. Eine Genotyp-Phänotyp-Korrelation konnte bislang nicht gezeigt werden.

\begin{tabular}{|c|c|}
\hline \multicolumn{2}{|l|}{ ABKÜRZUNGEN } \\
\hline 123J-IBZM-SPECT & $\begin{array}{l}\text { 123J-Jodbenzamid-Single-Photonen- } \\
\text { Emissions-Computertomografie }\end{array}$ \\
\hline $123 \mathrm{~J}-\beta$-CIT-SPECT & $\begin{array}{l}123 \mathrm{~J}-\beta \text {-Carbomethoxy-3} \beta-(4-i o d o p h e n y l) \\
\text { nortropan-Single-Photonen-Emissions- } \\
\text { Computertomografie }\end{array}$ \\
\hline CK & Kreatinkinase \\
\hline cox & Cytochrom C-Oxidase \\
\hline DGN & Deutsche Gesellschaft für Neurologie \\
\hline DXA & Dual Energy X-Ray Absorptiometry \\
\hline F 18 FDG-PET & $\begin{array}{l}18 \text { F-Fluordesoxyglukose-Positronen- } \\
\text { emissionstomografie }\end{array}$ \\
\hline Nfl & Neurofilament \\
\hline REC & relativ austauschbares Kupfer \\
\hline SCA & spinozerebelläre Ataxie \\
\hline TA & Transaminase \\
\hline THC & Tetrahydrocannabinol \\
\hline UWDRS & Unified Wilson's Disease Rating Scale \\
\hline
\end{tabular}




\section{FALLBEISPIEL}

\section{Fall 1: Unerwünschte Nebenwirkung der Therapie?}

Im 11. Lebensjahr Diagnose Morbus Wilson, Zufallsbefund infolge erhöhter Transaminasen (TA). Keine sonstigen Zeichen der hepatischen/neurologischen Manifestation. Unter Therapie (D-Penicillamin und Pyridoxinhydrochlorid) Normalisierung der TA und der Kupferbilanz. Bei normaler Kupferbilanz im 17. Lebensjahr belastungsabhängige Störungen des Sprechens und Schluckens, zunächst interpretiert als myasthene Reaktion im Sinne einer unerwünschten Nebenwirkung des D-Penicillamins.

\section{Klinischer Befund}

Dysarthrie, verminderte Zungenmotorik, Dysphagie

\section{Zusatzdiagnostik}

Abdomensonografie/cMRT normal. MRT des Mediastinums: Thymushyperplasie. 3-Hz-Serienstimulation mit signifikantem Decrement (bis 38\%) bei Ableitung an mehreren Muskeln. Autoantikörper gegen den Acetylcholinrezeptor stark positiv.

\section{Diagnosen}

- Morbus Wilson, u. a. molekulargenetisch gesichert.

- Antikörperpositive generalisierte Myasthenie mit faziopharyngealem Schwerpunkt als unabhängige (seltene) Zweiterkrankung.

- Endoskopische Thymektomie, Histologie: ausgeprägte lymphofollikuläre Hyperplasie, kein Anhalt für Thymom oder Malignität.

\section{Therapie und Verlauf}

Im weiteren Verlauf allmähliche Reduktion und Absetzen der symptomatischen Therapie (Pyridostigminbromid). Auch 4 Jahre nach Beendigung der Myasthenietherapie (keine Immunsuppression) und unter Fortsetzung der Morbus-WilsonTherapie klinisch komplett asymptomatisch, auch hinsichtlich des Morbus Wilson.

\section{HINTERGRUNDINFORMATION}

\section{Historisches}

Der Name der Erkrankung geht auf den britischen Neurologen Samuel Alexander Kinnier Wilson (1878-1937) zurück, der 1912 als erster die Erkrankung als Multisystemerkrankung verstanden und in seiner Dissertation als „progressive lenticular degeneration, a familiar, lethal neurologic disease accompanied by chronic liver disease leading to cirrhosis “ beschrieben hat [2].

Erste Mitteilungen über die Erkrankung stammen jedoch von Friedrich Theodor von Frerichs (1854) sowie Carl Friedrich Otto Westphal und Adolf von Strümpell (1898). Über Kupferablagerungen in der Kornea war durch die Augenärzte Bernhard Kayser und Bruno Fleischer bereits 1902 /1903 berichtet worden. Schließlich war es John Nathaniel Cumings, der 1948 einen gestörten Kupferstoffwechsel als Ursache der Erkrankung identifizierte. Mehrere Arbeitsgruppen lokalisierten das ATP7B-Gen 1993 auf dem langen Arm von Chromosom 13.

\section{Manifestation}

Üblicherweise manifestiert sich die Erkrankung zwischen dem 5. und 45. Lebensjahr [3], wenngleich sowohl über wesentlich frühere-im Säuglingsalter [4] als auch wesentlich spätere Manifestationen-im 70. Lebensjahr [5] berichtet wurde. Bis zur Pubertät findet sich in der Regel eine überwiegend hepatische Manifestation (ca. $40 \%$ der Fälle), nach der Pubertät bestimmen neurologische (ca. 40\% der Fälle) und psychiatrische (bis zu 10\% der Fälle) Befundabweichungen das klinische Bild, das wie der Krankheitsverlauf selbst in hohem Maße variabel ist.

Obwohl sich neurologisch 3 Subtypen voneinander abgrenzen lassen (pseudosklerotisch, parkinsonoid, hyperkinetisch-arrhythmisch), werden häufig Symptomkombinationen beobachtet. Gleichermaßen finden sich Mischformen mit neurologischer und hepatischer Symptomatik. Genetische, epigenetische und Umwelteinflüsse werden als mögliche Ursachen für die Variabilität der klinischen Präsentation und des Krankheitsverlaufs diskutiert, konnten bislang aber nicht zuverlässig aufgezeigt werden [6].

\section{FAZIT}

\section{Take Home Message}

Der Morbus Wilson manifestiert sich bis zur Pubertät überwiegend mit hepatischen Symptomen, nach der Pubertät und im Erwachsenenalter bestimmen in der Regel neurologische und psychiatrische Symptome das klinische Bild.

\section{Anamnese}

Den Morbus Wilson überhaupt in die differenzialdiagnostischen Erwägungen einzubeziehen ist entscheidend für die Diagnosestellung. Richtungsweisende Angaben lassen sich nur im Rahmen einer subtilen Anamneseerhebung fassen, da erste Symptome zunächst flüchtig und unspezifisch sein können. Das Spektrum ist groß und reicht im neurologisch-psychiatrischen Bereich von Berichten über „allgemeine Erschöpfung“, Stimmungsschwankungen, Ungeschicklichkeit bei feinmotorischen Abläufen, Veränderungen des Schriftbildes oder des Sprechens.

Erfragt werden müssen darüber hinaus Details aus der allgemeinen Krankengeschichte, da sich nicht selten Hinweise auf eine Hepatitis im Kindesalter und manifeste oder passagere Veränderungen des Blutbildes oder anderer Laborparameter finden lassen. Nach möglichen Problemen in der Alltagsbewältigung, in der Schule oder am Arbeitsplatz sollte ebenso gefahndet werden wie nach Veränderungen im Sozialverhalten, einschließlich der Partnerschaft. 


\section{Merke}

Unverzichtbar ist die Erhebung eines Stammbaums, um ggf. weitere Betroffene, insbesondere auch im präklinischen Stadium, zu identifizieren.

Kommt der Morbus Wilson differenzialdiagnostisch in Betracht, bietet es sich an, den Anamneseteil der Unified Wilson's Disease Rating Scale (UWDRS) anzuwen- den [6]. Mittels dreier Subskalen (neurologisch, psychiatrisch, internistisch) können Morbus-Wilson-typische Symptome gezielt abgefragt werden. Auf welche Symptomatik je nach Lebensalter besonders geachtet werden sollte, ist in $>$ Tab. 1 zusammengefasst [7].

> Tab. 1 Initialsymptomatik des Morbus Wilson nach Organbefall und Lebensalter [7].

\begin{tabular}{|c|c|c|}
\hline Organ/Organsystem & 5. Lebensjahr bis Beginn Pubertät & Pubertät bis 45 . Lebensjahr \\
\hline Leber & $\begin{array}{l}\text { asymptomatische geringe biochemische } \\
\text { Störungen (Bilirubinanstieg, Transamina- } \\
\text { senanstieg) } \\
\text { ikterische Schübe } \\
\text { Hepatosplenomegalie } \\
\text { virusnegative akute Hepatitis }\end{array}$ & $\begin{array}{l}\text { gezielte Anamnese: } \\
\text { vergessene Episoden von unklarer Hepati- } \\
\text { tis, länger zurückliegende ikterische } \\
\text { Schübe } \\
\text { unspezifische Diagnose: chronisch aktive } \\
\text { Hepatitis } \\
\text { klinisch asymptomatisch }\end{array}$ \\
\hline Blut/blutbildendes System & $\begin{array}{l}\text { Coombs-negative Hämolyse } \\
\text { („unklare“) Anämie, Leukopenie, Throm- } \\
\text { bopenie }\end{array}$ & meist leere Anamnese \\
\hline extrapyramidalmotorisches System & keine neurologischen Symptome & $\begin{array}{l}\text { Tremor, Ataxie } \\
\text { Schreibstörung } \\
\text { Dysarthrie } \\
\text { Dysphagie }\end{array}$ \\
\hline psychische und kognitive Störungen & Konzentrationsstörung & $\begin{array}{l}\text { Persönlichkeitsstörung } \\
\text { Verhaltensstörung } \\
\text { kognitiver Leistungsabfall }\end{array}$ \\
\hline Augen & $\begin{array}{l}\text { diskreter/unvollständiger Kayser-Flei- } \\
\text { scher-Kornealring }\end{array}$ & $\begin{array}{l}\text { diskreter/unvollständiger Kayser-Flei- } \\
\text { scher-Kornealring }\end{array}$ \\
\hline
\end{tabular}

\section{FALLBEISPIEL}

\section{Fall 2: Therapieunregelmäßigkeiten? Anamnese}

Im 5. Lebensjahr nach Toxoplasmoseinfektion aufgrund persistierender Erhöhung der Transaminasen (4-fach) und Hepatosplenomegalie erweiterte Diagnostik mit dem Ergebnis Morbus Wilson. Unter Therapie mit D-Penicillamin und Pyridoxinhydrochlorid TA-Erhöhung rückläufig, aber zu keinem Zeitpunkt Normalisierung, normale Kupferbilanz im 24-h-Sammelurin. Im Verlauf zeitweise Therapieunregelmäßigkeiten mit der Folge einer Leberzirrhose (Child B).

Im 29. Lebensjahr Vorstellung in der Notaufnahme aufgrund von Thoraxschmerzen.

\section{Befunde}

Ausschluss kardiopulmonaler Ursachen. Laborchemisch Erhöhung der TA (4 - bis 6-fach), Hyper-CKämie (50-fach) und erhöhtes Myoglobin (7-fach). Keine Paresen. Keine Muskelatrophien. Keine relevanten Myalgien. Elektromyografie (M. deltoideus und $\mathrm{M}$. quadriceps femoris) mit regelrechtem Befund.

\section{Molekulargenetische Diagnostik}

- Nachweis zweier pathogener Mutationen im ATB7B-Gen:

- Exon 14: c.3207C>A (p.His1069GIn)

- Exon 20: c.4092_4093delGT (p. Ser1365Cysfs*12) und

- Nachweis zweier pathogener Mutationen im PYGMGen:

- c.148C>T; p.Arg50* (het.) und

- c.2056G>A; p.Gly686Arg (het.).

\section{Diagnosen}

- Morbus Wilson, unter Therapie mit Trientindihydrochlorid klinisch asymptomatisch, normale Kupferbilanz. In der Abdomensonografie einschließlich Fibroscan Zeichen der Leberzirrhose, seit Jahren stabiler Befund.

- Morbus McArdle (Glykogenose Typ V), im vorliegenden Fall mit sehr moderatem klinischen Verlauf. Eine spezifische Therapie steht nicht zur Verfügung. 


\section{Diagnostik}

\section{Klinische Befunde}

Die Vielfalt der möglichen Symptome und der mögliche systemische Befall sind in den Übersichten dargestellt.

Um relevante klinische Symptome nicht zu übersehen oder gar fehlzuinterpretieren, sollte die Befunderfassung standardisiert erfolgen. Sowohl die Unified Wilson's Disease Rating Scale (UWDRS) als auch der „Neurologie-Score“ $[10,11]$ sind geeignete Messinstrumente, die sich jedoch wesentlich im Umfang und ihrer Praktikabilität im klinischen Alltag unterscheiden. Während die UWDRS neurologische, psychiatrische und internistische Befunde mit insgesamt 55 Items erfasst, basiert der „Neurologie-Score“ allein auf der klinisch neurologischen Untersuchung ( $>$ Tab.2, nach [11]).

Der Neurologie-Score erfasst 8 extrapyramidale Symptome, die mittels eines Punktesystems - asymptomatisch (0 Punkte), leicht (2 Punkte) bis sehr schwer (5 Punkte) - beurteilt werden, wobei der Summenscore, abgesehen von der Dysarthrie, nicht auf einzelne Befunde schließen lässt. Der Schweregrad der neurologischen Beeinträchtigung ergibt sich aus der Summe aller Punkte.

\section{Merke}

Anamneseerhebung und Befunderfassung sollten aufgrund der großen Variabilität der Manifestationen standardisiert erfolgen. Tremor und Feinmotorikstörungen sind häufig richtungsweisende Frühsymptome einer neurologischen Manifestation.

Nahezu pathognomonisch für einen Morbus Wilson ist der Kayser-Fleischer-Kornealring, der gelegentlich auch ohne Untersuchung an der Spaltlampe zu sehen ist ( $\triangleright$ Abb. 1). Er entwickelt sich erst, wenn Kupfer aus der Leber freigesetzt wird, sodass er bei Kindern meist nicht nachweisbar ist. Fehlt er, ist die Diagnose Morbus Wilson nicht ausgeschlossen. Gleiches gilt für die eher selten vorkommende Sonnenblumenkatarakt ( Abb. 2).

\section{Laborchemische Befunde}

Sobald der klinische Verdacht Morbus Wilson gestellt ist, muss sich die laborchemische Analyse der Kupferstoffwechselparameter anschließen. Als typische Laborkonstellation gilt ein erniedrigtes Serumkupfer bei erhöhtem Anteil des freien Kupfers, ein erniedrigtes Coeruloplasmin und eine erhöhte basale Kupferausscheidung im 24-h-Sammelurin. Entsprechende Normwerte sind in $>$ Tab. 3 aufgeführt, wobei die Referenzbereiche von Labor zu Labor abweichen können [812].

\section{ÜBERSICHT}

$\begin{array}{lc}\text { Neurologische und neuropsychologische/ } & \text { - Hyposmie } \\ \text { psychiatrische Manifestationen des Morbus } & \text { " selten zerebrale Anfälle } \\ \text { Wilson } & - \text { epileptisch } \\ \text { Neurologisch } & - \text { Hirnstammanfälle }\end{array}$

- Motorik-Frühsymptome

- Halte-, Aktions- und Intentionstremor mehr als Ruhetremor

- Dysarthrie und Dysphagie

- Makro- mehr als Mikrografie

- Koordinationsstörungen, insbesondere bei rasch alternierenden Bewegungsabläufen

- Störungen der Feinmotorik

- Motorik-im weiteren Verlauf

- Gangstörungen

- hypokinetisch rigide

- dyston

- ataktisch

- Tonusveränderungen

- Rigor

- Dystonie

- (selten) Spastik

- weitere

- Hirnstammanfälle

\section{Neuropsychologisch/psychiatrisch}

- Belastungsintoleranz

- kognitive Defizite (insbesondere Gedächtnis- und Konzentrationsstörungen)

- Verhaltens- und Persönlichkeitsstörungen

- Stimmungsschwankungen

- depressiv

- dysthym

- manisch

- Störungen der Emotionalität und der Impulskontrolle

- Störungen des Sexualverhaltens

- Schlafstörungen

- Psychosen

- manisch/depressiv

- paranoid-halluzinatorisch

(nach [8])

- Hypomimie

- Hypersalivation 


\section{ÜBERSICHT}

Extrazerebrale Manifestationen des Morbus Wilson

Leber

- laborchemische (asymptomatische) Veränderungen, z. B. Erhöhung der Transaminasen

- Steatosis hepatis

- akute oder chronisch aktive Hepatitis

- Leberfibrose und Leberzirrhose inklusive deren Komplikationen

- akutes/fulminantes Leberversagen

\section{Augen}

- Kayser-Fleischer-Kornealring

- Sonnenblumenkatarakt

- (sekundäre) Hemeralopie (Schwierigkeit, im hellen Licht klar zu sehen)

\section{Andere Organsysteme}

- Endokrinium

- Infertilität

- testikuläre Dysfunktion

- Menstruationsstörungen/Amenorrhöe

- Aborte

- Hypoparathyreoidismus

- muskuloskelettales System

- Arthropathien/Arthritis

- Osteoporose

- kupferinduzierte Rhabdomyolyse
- hypokaliämische Muskelschwäche

- Niere

- tubuläre Funktionsstörungen (renal bis Fanconi-Syndrom, proximale und oder distale tubuläre Dysfunktion)

- Hämaturie

- Proteinurie

- gastrointestinales System

- Cholelithiasis

- Pankreatitis, exokrine Pankreasinsuffizienz

- spontane bakterielle Peritonitis

- Herz

- Kardiomyopathie

- Herzrhythmusstörungen

- autonome Funktionsstörungen

- Blutbildung

- Coombs-negative Hämolyse

- Anämie

- Folgeschäden der Leber- (Koagulopathie) und der Milzfunktionsstörung (Thrombozytopenie, Leukopenie)

- Haut

- blaue Lunulae

- Hyperpigmentierung

- vermehrt subkutane Lipome

(nach [8])

\Tab.2 Neurologie-Score zur Verlaufsbeurteilung beim Morbus Wilson.

\begin{tabular}{|c|c|c|}
\hline Symptomatik & \multicolumn{2}{|l|}{ Bewertung } \\
\hline \multicolumn{3}{|c|}{ Extrapyramidale Symptome } \\
\hline \multirow{4}{*}{$\begin{array}{l}\text { Feinmotorik } \\
\text { Diadochokinese } \\
\text { Ruhe-/Haltetremor } \\
\text { Tonuserhöhung } \\
\text { Brady-/Hypokinese } \\
\text { Ataxie } \\
\text { Gangstörung }\end{array}$} & sehr schwer & 5 Punkte \\
\hline & schwer & 4 Punkte \\
\hline & mäßig & 3 Punkte \\
\hline & leicht & 2 Punkte \\
\hline \multicolumn{3}{|l|}{ Dysarthrophonie } \\
\hline Dysarthrophonie & vorhanden & 1 Punkt \\
\hline keine Dysarthrophonie & - & 0 Punkte \\
\hline
\end{tabular}




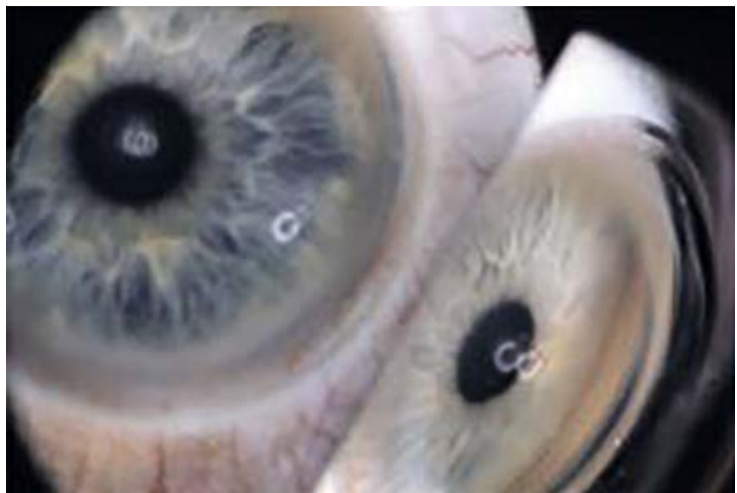

Abb. 1 Kayser-Fleischer-Kornealring (Quelle: Reuner U, Huster D. Therapie des Morbus Wilson. In: Höglinger GU, Hrsg. Parkinson-Syndrome kompakt, Diagnostik und Therapie in Klinik und Praxis. Stuttgart: Thieme; 2019).

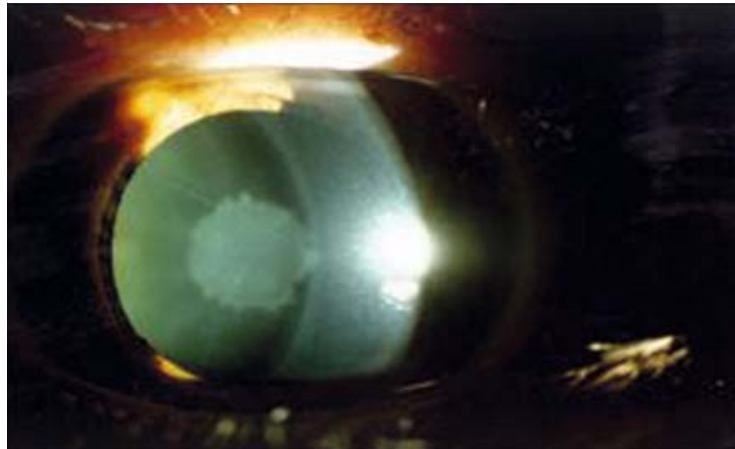

- Abb. 2 Sonnenblumenkatarakt (Quelle: Reuner U, Huster D. Therapie des Morbus Wilson. In: Höglinger GU, Hrsg. Parkinson-Syndrome kompakt, Diagnostik und Therapie in Klinik und Praxis. Stuttgart: Thieme; 2019)

> Tab. 3 Normwerte des Kupferstoffwechsels [8, 12].

\begin{tabular}{|c|c|c|}
\hline Parameter & SI-Einheit & Sonstige Einheit \\
\hline \multicolumn{3}{|l|}{ Kupfer im Serum (adult) } \\
\hline Männer & $12,4-20,6 \mu \mathrm{mol} / \mathrm{l}$ & $79-131 \mu \mathrm{g} / \mathrm{dl}$ \\
\hline Frauen & $11,6-19,2 \mu \mathrm{mol} / \mathrm{l}$ & $74-122 \mu \mathrm{g} / \mathrm{dl}$ \\
\hline Coeruloplasminkupfer $(\mathrm{Cp}-\mathrm{Cu})^{1}$ & - & >90\% des Serumkupfers \\
\hline freies Kupfer $(\mathrm{fCu})^{2}$ & $<1,5 \mu \mathrm{mol} / \mathrm{l}$ & $<10 \mu \mathrm{g} / \mathrm{dl}$ \\
\hline Coeruloplasmin & $0,20-0,60 \mathrm{~g} / 1$ & $20-60 \mathrm{mg} / \mathrm{dl}$ \\
\hline $\begin{array}{l}\text { Urinkupfer } \\
\text { Kupfer im Urin pro Tag }\end{array}$ & $\begin{array}{l}<1,0 \mu \mathrm{mol} / \mathrm{l} \\
0,20-0,60 \mu \mathrm{mol} / 24 \text { Std. }\end{array}$ & $<65 \mu \mathrm{g} / \mathrm{dl}$ \\
\hline Leberkupfer $^{4}$ & keine Angabe & $<50 \mu \mathrm{g} / \mathrm{g}$ Trockengewicht \\
\hline \multicolumn{3}{|c|}{$\begin{array}{l}{ }^{1} \text { Berechnung nach der Formel: } \mathrm{Cp}-\mathrm{Cu}(\mu \mathrm{g} / \mathrm{dl})=\mathrm{Cp}(\mathrm{mg} / \mathrm{dl}) \times 3 \text {. } \\
2 \text { Berechnung nach der Formel: } \mathrm{fCu}(\mu \mathrm{g} / \mathrm{dl})-3 \times \mathrm{Cp} \mathrm{mg/dl}) ; \mathrm{fCu}(\mu \mathrm{mol} / \mathrm{l})=\mathrm{Cu}(\mu \mathrm{mol} / \mathrm{l})-53 \times \mathrm{Cp}(\mathrm{g} / \mathrm{l}) \text {. } \\
{ }^{3} \text { Laborwert UK Dresden, persönliche Mitteilung. } \\
{ }^{4} \text { Bei Neugeborenen physiologisch stark erhöht. }\end{array}$} \\
\hline
\end{tabular}

\section{Cave}

Normale Leberwerte schließen einen Morbus Wilson nicht aus.

Ein ergänzender D-Penicillamin-Belastungstest ist dann sinnvoll, wenn die Ergebnisse der basalen Kupferausscheidung nicht eindeutig sind. Steigt die Kupferausscheidung nach D-Penicillamin-Provokation gegenüber dem Ausgangswert um das ca. 20-Fache, wird die Verdachtsdiagnose unterstützt.

\section{Merke}

Erniedrigtes Kupfer im Serum mit erhöhtem Anteil des freien Kupfers, erniedrigtes Coeruloplasmin im Serum und eine erhöhte basale Kupferausscheidung im 24-h-Sammelurin sprechen für die Verdachtsdiagnose Morbus Wilson.
Ein vergleichsweise neuer sensitiver und spezifischer Marker für die Diagnostik des Morbus Wilson ist das relative austauschbare Kupfer (relative exchangeable Copper, REC), also der locker an Albumin gebundene Anteil des Kupfers, der mittels Chelator leicht extrahiert und gemessen werden kann. Bezogen auf die Gesamtkupferkonzentration im Serum (Quotient aus austauschbarem Kupfer/Gesamtkupfer) ergibt sich die Ratio (REC). El Balkhi und Mitarbeiter [13] konnten zeigen, dass durch diesen Marker alle Patienten mit Morbus Wilson von heterozygoten Anlageträgern und gesunden Personen unterschieden werden konnten, was sich auch in Familienscreenings bestätigten ließ [14]. 


\section{Molekulargenetische Diagnostik}

Die molekulargenetische Diagnostik kann ein wesentlicher Baustein in der Diagnostik sein. Sie sollte aber nur bei klinisch begründetem Verdacht veranlasst werden. Coffey und Mitarbeiter [15] konnten zeigen, dass bei Sequenzierung aller codierenden Regionen und benachbarten Splice-Orte von ATP7B in 98\% der Fälle mit Verdacht auf Morbus Wilson die Identifikation der Mutationen möglich ist. Bei der Befundinterpretation muss allerdings immer berücksichtigt werden, dass infolge der hohen Zahl der beschriebenen Mutationen (http://www.wilsondisease.med.ualberta.ca/database. asp [Stand: 11.01.2021]) Sense- oder Silent-Mutationen möglich sind, die nicht zu einer klinischen Manifestation führen [6]. Von daher besteht die Gefahr einer Über- bzw. Fehlinterpretation der Befunde.

\section{FAZIT}

\section{Take Home Message}

Der Morbus Wilson wird autosomal-rezessiv vererbt. Deshalb sollte bei klinisch begründetem Verdacht eine molekulargenetische Diagnostik veranlasst werden. Der Genort befindet sich auf dem langen Arm von Chromosom 13.

\section{Bildgebende Diagnostik}

\section{Merke \\ Die zerebrale Magnetresonanztomografie ist bei Verdacht auf Morbus Wilson obligat. Signalverän- derungen werden bei nahezu allen neurologisch manifesten Patienten gefunden.}

Wenngleich die MRT-Befunde unspezifisch und ausgesprochen variabel sind, betreffen sie regelhaft die Basalganglien, den Pons und das Zerebellum. Als typisch gelten Signalveränderungen der Putamina in T2-gewichteten Sequenzen ( $\triangleright$ Abb.3) und multilokuläre Atrophien. Die Mittelhirnatrophie kommt bei axialer Schnittführung als sog. Pandabär-Zeichen zur Darstellung [16] (> Abb.4).

\section{Nuklearmedizinische Verfahren}

In ausgewählten Fällen können für die Diagnosestellung nuklearmedizinische Untersuchungen, z. B. die 18 F-Fluordesoxyglukose PET (F 18 FDG-PET), hilfreich sein. Neurologisch manifeste Patienten haben einen signifikant verminderten Glukosemetabolismus, regional mehr als global, wobei das Caput nuclei caudati [17] häufig am schwersten betroffen ist ( $\mathbf{A b b}$. 5).
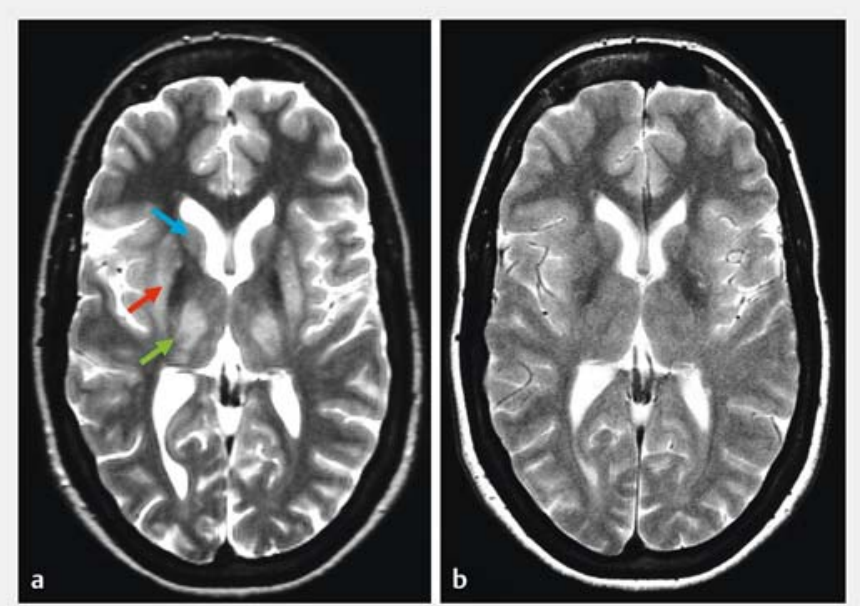

Abb. 3 MRT-Befund bei Morbus Wilson, axiale T2-Sequenz. a Bilaterale symmetrische Hyperintensitäten im Caudatuskopf (blauer Pfeil), Putamen (roter Pfeil) und Thalamus (grüner Pfeil). b Rückbildung der Veränderungen nach Therapie (Quelle: Reuner U, Huster D. Therapie des Morbus Wilson. In: Höglinger GU, Hrsg. Parkinson-Syndrome kompakt, Diagnostik und Therapie in Klinik und Praxis. Stuttgart: Thieme; 2019).

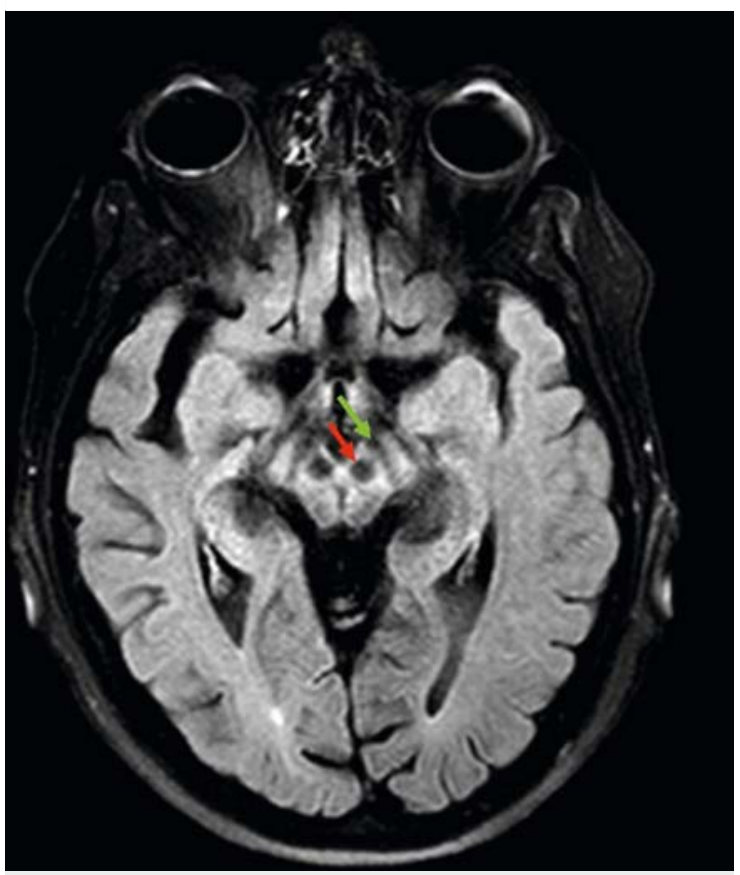

Abb. 4 Axiale T1-Sequenz: Das Bild zeigt die Substantia nigra (grüner Pfeil) und den Nucleus ruber (roter Pfeil), umrandet von hyperintensem Parenchym im Mittelhirn (Pandabär-Zeichen) (Quelle: Reuner U, Huster D. Therapie des Morbus Wilson. In: Höglinger GU, Hrsg. ParkinsonSyndrome kompakt, Diagnostik und Therapie in Klinik und Praxis. Stuttgart: Thieme; 2019). 

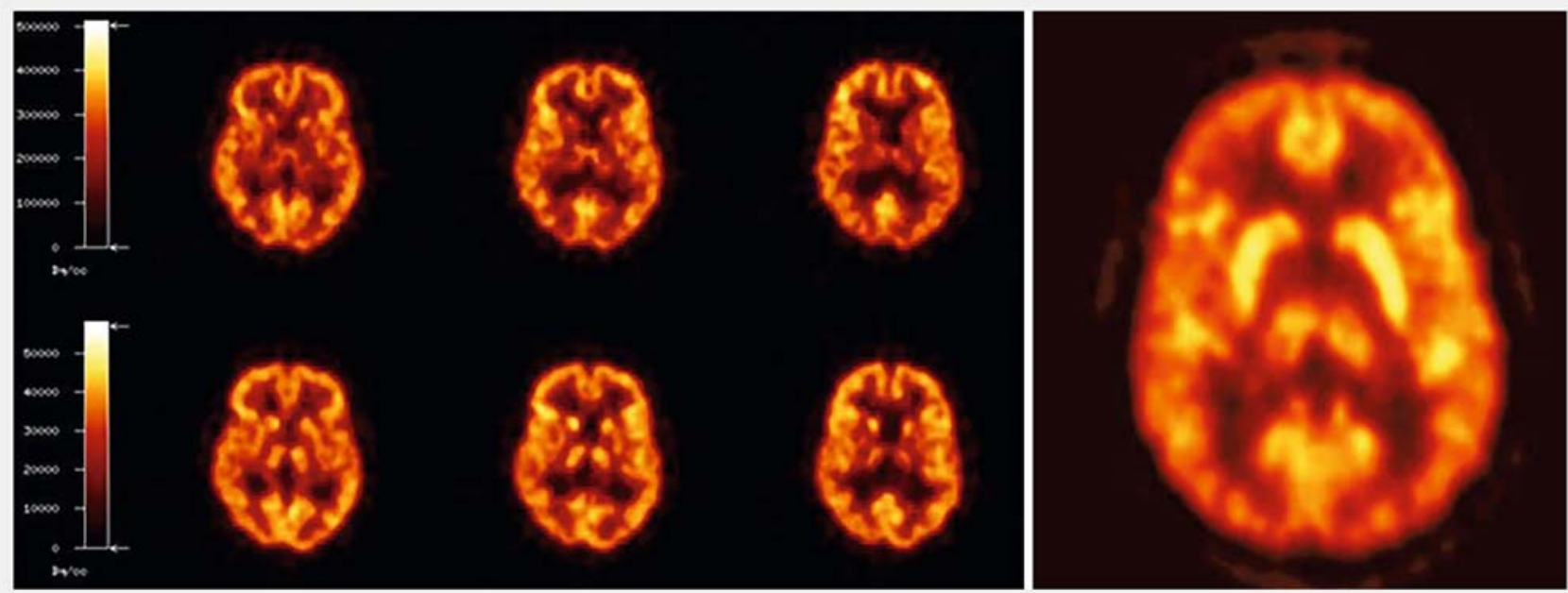

Abb.5 18 F-FDG-PET (18 F-Fluordesoxyglukose-Positronenemissionstomografie) einer neurologisch manifesten Wilson-Patientin vor (obere Reihe) und nach 2 Jahren Therapie (untere Reihe und Bildausschnitt) mit initial stark vermindertem Glukoseumsatz in den Basalganglien und Normalisierung unter Therapie.

Mittels Szintigrafie (123J- $\beta$-CIT-SPECT und 123J-IBZMSPECT) können darüber hinaus prä- und postsynaptische Funktionen des nigrostriatalen Systems untersucht werden, wobei bei neurologisch manifesten Patienten eine verminderte postsynaptische Impulsdichte gefunden werden kann.

\section{Weitere neurologische Zusatzuntersuchungen}

Die transkranielle Sonografie (Beurteilung der Echogenität des Nucleus lentiformis) und elektrophysiologische Untersuchungen (evozierte Potenziale) sind als nichtinvasive Verfahren zur Verlaufskontrolle und weniger zur Diagnostik geeignet [18].

\section{Ergänzende internistische Untersuchungen}

Die Abdomensonografie, insbesondere die Beurteilung der Leber, einschließlich der Leberelastizitätsmessung, hat einen hohen Stellenwert im Rahmen der Diagnostik und zur Verlaufsbeurteilung einer zusätzlichen hepatischen Manifestation. Meist werden beide Verfahren kombiniert angewandt. Sie erlauben Aussagen zum Grad der Fibrose oder Zirrhose und vermutlich auch zur Prognose der Lebererkrankung [19].

Auf eine Leberbiopsie kann, insbesondere im Kontext der neurologischen Manifestation, häufig verzichtet werden. Als invasives Verfahren sollte sie möglichst nur bei unklarer Befundlage angewandt werden, zumal das histologische Bild sehr heterogen und unspezifisch sein kann [6].

\section{Wichtige neurologische Differenzialdiagnosen}

Unter Berücksichtigung der klinischen Symptomatik und des Manifestationsalters kommen differenzialdiagnostisch extrapyramidal motorische (z. B. juvenile Parkinson-Syndrome) einschließlich Tremorerkrankungen (z. B. essenzieller Tremor) in Betracht. Stehen Hyperkinesen und Dystonie im Vordergrund der Symptomatik, sollten fokale und generalisierte Dystonien, erworbene und genetisch bedingte Chorea-Erkrankungen und die sehr seltenen Neuroakanthozytosen bedacht werden. Häufigste Differenzialdiagnosen zerebellärer Störungen, insbesondere der Ataxie, sind die Multiple Sklerose und als genetisch determinierte Erkrankungen die spinozerebellären Ataxien (SCA), wie z.B. die SCA 1, 2 oder 3 mit unvollständiger Penetranz und dadurch nicht klarem autosomal-dominanten Erbgang.

\footnotetext{
Merke

Aufgrund der vielgestaltigen neurologischen Symptomatik sind extrapyramidal-motorische, einschließlich Tremorerkrankungen, Dystonien sowie Erkrankungen des Kleinhirns abzugrenzen.
}

Ein Vorschlag zur Stufendiagnostik des Morbus Wilson ist in $>$ Abb. $\mathbf{6}$ dargestellt. 


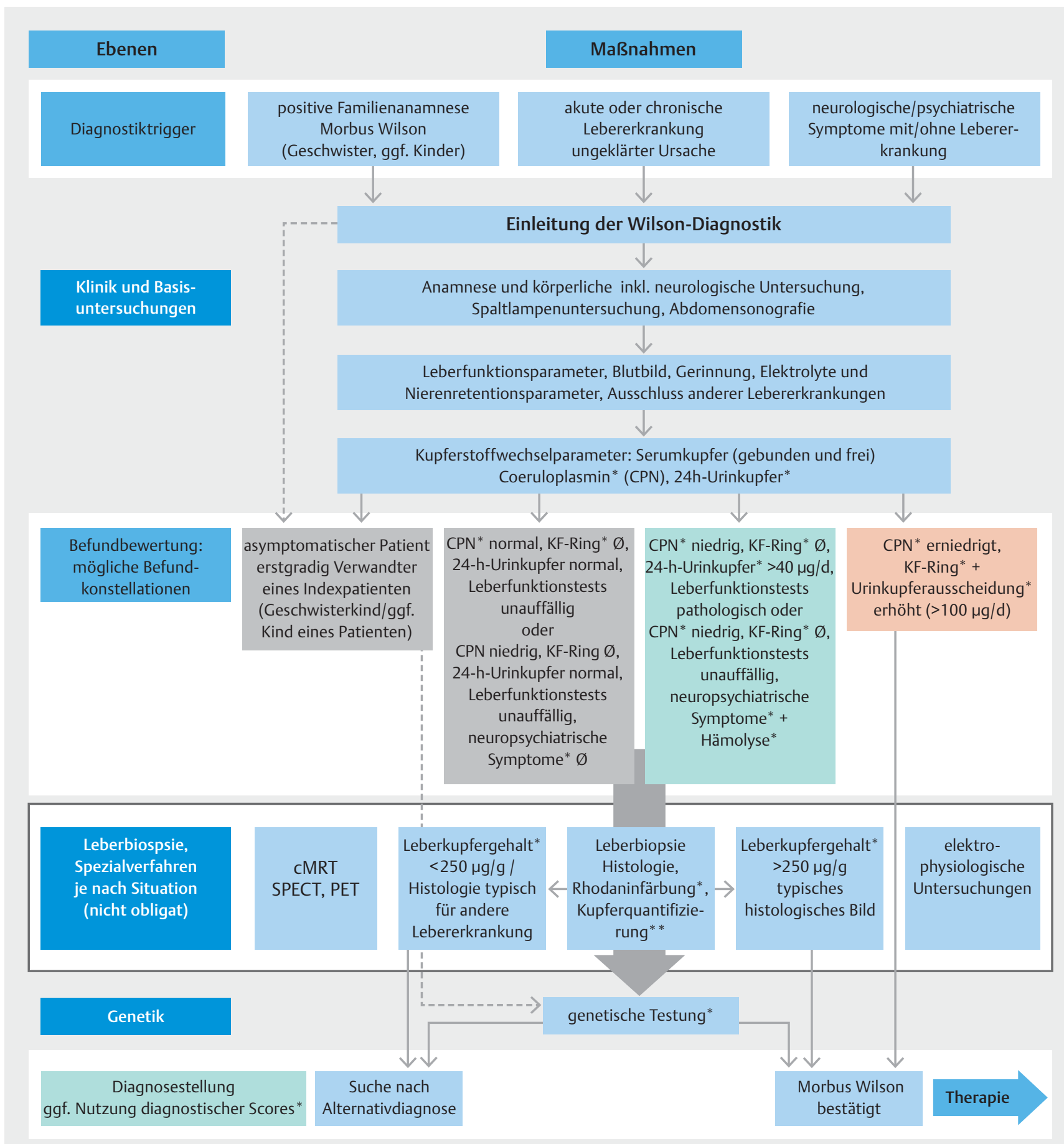

Abb. 6 Stufendiagnostik bei V.a. Morbus Wilson (Quelle: Reuner U, Huster D. Therapie des Morbus Wilson. In: Höglinger GU, Hrsg. ParkinsonSyndrome kompakt, Diagnostik und Therapie in Klinik und Praxis. Stuttgart: Thieme; 2019). ${ }^{*}=$ Scores, UWDRS, Neurologiescore, Score; cMRT = MRT des Schädels; CPN = Coeruloplasmin; KF= Kayser-Fleischer-Kornealring; PET = Positronenemissionstomografie; SPECT = EinzelphotonenEmissionscomputertomografie 


\section{Diagnoseüberprüfung mittels Leipzig-Score}

Ist die Diagnose Morbus Wilson nach anamnestischen Angaben und klinischen Befunden wahrscheinlich, kann die Diagnose mittels des sog. Leipzig Scores ( Tab.4), der klinische und paraklinische Befunde zusammenführt, in der Regel zuverlässig gestellt werden. Eine Schwäche des Scores besteht allerdings darin, dass die neurologische Manifestation nur allgemein mit „neurologische(n) Symptome(n)“ beschrieben wird und nicht speziell extrapyramidal-motorische und/ oder zerebelläre Symptome gefordert sind und darüber hinaus psychopathologische Befunde nicht erfasst werden. Der Nachweis zweier Mutationen ist mit 4 Punkten (über-)bewertet, sodass sich damit formal die Diagnose allein molekulargenetisch und ohne klinischen Bezug stellen ließe. Zur Diagnosestellung gehören in jedem Fall klinische und/oder paraklinische Befundabweichungen, da Sense- und Silent-Mutationen, die keine klinische Relevanz besitzen, möglich sind und so zu einer falsch positiven Diagnose führen können.

\section{Besondere Lebenssituationen}

Pubertät und Transitionsphase von der Kinder- und Jugendmedizin in den Erwachsenenbereich bedürfen, ebenso wie Schwangerschaft und Stillperiode, besonderer Aufmerksamkeit und Sensibilität. Besonders wichtig sind Aufklärung und Motivation zur „Therapietreue“ als Garant für einen lebenslangen stabilen Verlauf.

Sofern die Therapie konsequent fortgeführt und gut interdisziplinär überwacht wird, gelten auch Schwangerschaft und Stillperiode als sicher [21,22]. Idealerweise sollte die „Entkupferung“ vor Eintritt einer Schwangerschaft abgeschlossen sein. Stillen wird zwar nicht empfohlen, im klinischen Alltag jedoch häufig „erlaubt“ und praktiziert, ohne dass bislang über Probleme berichtet wurde $[6,22,23]$. Tab. 4 Leipzig Score zur Diagnosestellung des Morbus Wilson (8th International Conference on Wilson's disease and Menkes disease.
Leipzig/Germany, April $16-18,2001 ;[8,20]$ ).

\begin{tabular}{|c|c|c|c|}
\hline \multirow[t]{2}{*}{ Parameter } & \multicolumn{3}{|c|}{ Zugeordneter Punktwert } \\
\hline & 0 & 1 & 2 \\
\hline neurologische Symptome & fehlend & mild & schwer \\
\hline Kayser-Fleischer-Kornealring & fehlend & - & vorhanden \\
\hline Coombs-negative hämolytische Anämie & fehlend & vorhanden & - \\
\hline Kupferausscheidung im Urin & normal & 1 -bis 2 -fach erhöht & $>2$-fach erhöht \\
\hline $\begin{array}{l}\text { Leberkupfer, quantitativ } \\
\text { (normal: }<50 \mu \mathrm{g} / \mathrm{g} \text { Trockengewicht) }\end{array}$ & normal-1 Punkt & $50-249 \mu \mathrm{g} / \mathrm{g}$ & $>250 \mu \mathrm{g} / \mathrm{g}$ \\
\hline Leberkupfer, Rhodaninfärbung & fehlend & vorhanden & - \\
\hline $\begin{array}{l}\text { Coeruloplasmin } \\
\text { (normal }>0,2 \mathrm{~g} / \mathrm{l} \text { ) }\end{array}$ & normal & $0,1-0,2 \mathrm{~g} / \mathrm{l}$ & $<0,1 \mathrm{~g} / \mathrm{l}$ \\
\hline Mutationsnachweis & negativ & $\begin{array}{l}\text { Nachweis auf einem } \\
\text { Chromosom } \\
1 \text { Punkt }\end{array}$ & $\begin{array}{l}\text { Nachweis auf } 2 \text { Chromo- } \\
\text { somen oder compound- } \\
\text { heterozygot } \\
4 \text { Punkte }\end{array}$ \\
\hline \multicolumn{4}{|l|}{ Auswertung } \\
\hline Score & \multicolumn{3}{|c|}{ Wahrscheinlichkeit der Diagnose } \\
\hline 4 Punkte & \multicolumn{3}{|c|}{ Diagnose hochwahrscheinlich/sicher } \\
\hline 2 - 3 Punkte & \multicolumn{3}{|c|}{ Diagnose möglich, weitere Untersuchungen notwendig } \\
\hline 0-1 Punkt & \multicolumn{3}{|c|}{ Diagnose unwahrscheinlich } \\
\hline
\end{tabular}


FALLBEISPIEL

\section{Fall 3: Seltene Manifestation}

\section{Anamnese}

Im 26. Lebensjahr nach bis dahin unauffälliger Vorgeschichte über Monate hinweg Alkoholmissbrauch und gelegentlicher Konsum von Tetrahydrocannabinol (THC), Verwahrlosungstendenzen. Aufgrund von Verfolgungs- und Beziehungserleben mit entsprechenden Ängsten und Fremdaggressivität Vorstellung in der Notaufnahme. Es besteht der V.a. drogeninduzierte Psychose, DD paranoide Schizophrenie.

\section{Diagnostisches und therapeutisches Vorgehen} Unter symptomatischer Therapie mit atypischen Neuroleptika rasch Demaskierung eines grobschlägigen Tremors, irregulärer dystoner Bewegungsstörungen der Finger und Füße, Dysarthrie und Dysphagie. Im Rahmen der Diagnostik typische Labor- konstellation und cMRT-Befunde wie bei Morbus Wilson.

Diagnosesicherung u. a. molekulargenetisch mit dem Nachweis zweier pathogener Mutationen im ATB7B-Gen. Unter Therapie mit D-Penicillamin in niedriger (!) Dosierung und Pyridoxinhydrochlorid Destabilisierung mit Zunahme der neurologischen Defizite. Umstellung auf Trientindihydrochlorid und Fortsetzung der symptomatischen antipsychotischen Therapie. Erst nach Monaten Befindensstabilisierung und Rückläufigkeit der psychiatrischen und neurologischen Symptomatik.

\section{Diagnosen}

Morbus Wilson, Manifestation mit organisch affektiver Störung mit paranoider Ausweitung, extrapyramidal-motorischer neurologischer und (subklinisch) hepatischer Komponente (Leberfibrose im B-Bild und im Fibroscan).
Cave

Während einer Schwangerschaft darf die Wilsonspezifische Therapie nicht unterbrochen werden. Sowohl die Therapie mit Chelatbildnern als auch mit Zinksalzen wird in der Regel von Mutter und Kind gut vertragen.

\section{Therapie und Therapiekontrolle}

Ist die Diagnose Morbus Wilson einmal gestellt, sollte die Therapie unabhängig von der aktuellen Symptomatik unverzüglich eingeleitet und lebenslang fortgeführt werden. Das gilt sowohl für symptomatische Patienten als auch für Betroffene, die klinisch noch asymptomatisch und z. B. nur im Rahmen eines Familienscreenings identifiziert worden sind.

\section{Cave}

Die Therapie darf nie für einen längeren Zeitraum unterbrochen werden, auch nicht im Rahmen einer Schwangerschaft oder während der Stillzeit, da eine erneute Kupferakkumulation und symptomatische Verschlechterungen bis hin zu irreversiblen neurologischen Defiziten oder fulminantem Leberversagen drohen.

Die Wahl des Medikamentes, Dosierungen und der Therapieplan überhaupt sind individuelle Entscheidungen, da keine kontrollierten Vergleichsstudien vorliegen.
Grundsätzlich orientiert sich die Therapie an nationalen und internationalen Leitlinien und Praxisempfehlungen [1, 24-26]. Sie umfasst sowohl medikamentöse als auch nicht-medikamentöse Maßnahmen, sie muss lebenslang erfolgen und im Verlauf regelmäßig hinsichtlich ihrer Wirksamkeit und Sicherheit überprüft und, falls erforderlich, angepasst werden.

Das Behandlungsziel besteht im Erreichen und der Aufrechterhaltung einer normalen Kupferhomöostase durch Erhöhung der renalen Kupferelimination und Reduktion der enteralen Kupferresorption. Dazu stehen verschiedene Substanzen mit unterschiedlichen Wirkmechanismen zur Verfügung (s. a. - Tab.5).

\section{Spezifische medikamentöse Therapie des Morbus Wilson}

Einer initialen Phase der Entkupferung (Induktionstherapie) schließt sich eine dauerhafte Erhaltungstherapie an. Kupferchelatoren werden sowohl zur Therapieeinleitung als auch in der Langzeittherapie (dann so niedrig wie möglich dosiert) eingesetzt. Zinksalze hingegen eignen sich besonders zur Erhaltungstherapie. Sie werden aber auch im präklinischen Stadium, insbesondere bei Kindern, erfolgreich eingesetzt $[25,26]$. 
- Tab. 5 Übersicht über die spezifische medikamentöse Therapie beim Morbus Wilson. (Quelle: Reuner U, Huster D. Therapie des Morbus Wilson. In: Höglinger GU, Hrsg. Parkinson-Syndrome kompakt, Diagnostik und Therapie in Klinik und Praxis. Stuttgart: Thieme; 2019)

\begin{tabular}{|c|c|c|c|c|}
\hline Medikament & Mechanismus & Standarddosis & Vorteile & Nachteile \\
\hline D-Penicillamin & $\begin{array}{l}\text { Chelator, gesteigerte } \\
\text { renale Eliminierung }\end{array}$ & $\begin{array}{l}0,9-1,5 \mathrm{~g} / \text { Tag, } \\
2 \text { - } 3 \text { Dosen, getrennt } \\
\text { von den Mahlzeiten } \\
\text { Maximaldosis } 2,4 \mathrm{~g} / \mathrm{Tag}, \\
\text { „einschleichende“ } \\
\text { Dosierung } \\
\text { Vitamin-B }{ }_{6} \text {-Substitution } \\
\text { erforderlich }\end{array}$ & $\begin{array}{l}\text { hocheffektiv, schneller } \\
\text { Wirkungseintritt, lange } \\
\text { Erfahrung } \\
\text { vergleichsweise kosten- } \\
\text { günstig }\end{array}$ & $\begin{array}{l}\text { mögliche Verstärkung } \\
\text { neurologischer Symptome } \\
\text { bei Therapiebeginn } \\
\text { mögliche systemische NW: } \\
\text { u.a. Proteinurie, Blutbild- } \\
\text { veränderungen, allergi- } \\
\text { sche Reaktionen }\end{array}$ \\
\hline $\begin{array}{l}\text { Trientine-dihydrochlorid } \\
\text { (Cave: } 200 \text { mg Wirkstoff) } \\
\text { Trientine-tetrahydrochlo- } \\
\text { rid } \\
\text { (Cave: } 150 \text { mg Wirkstoff) } \\
\text { Keine } 1: 1 \text { Umstellung } \\
\text { möglich! }\end{array}$ & $\begin{array}{l}\text { Chelator, gesteigerte re- } \\
\text { nale Eliminierung und in } \\
\text { geringem Ausmaß auch } \\
\text { Reduktion der Kupfer- } \\
\text { resorption }\end{array}$ & $\begin{array}{l}1-1,5 \mathrm{~g} / \mathrm{Tag}, 2-4 \text { Dosen, } \\
\text { getrennt von den Mahlzei- } \\
\text { ten } \\
\text { Maximaldosis } 2,4 \mathrm{~g} / \text { Tag } \\
\text { "einschleichende“ } \\
\text { Dosierung }\end{array}$ & $\begin{array}{l}\text { effektiv und wohl weniger } \\
\text { Nebenwirkungen als } \\
\text { D-Penicillamin }\end{array}$ & $\begin{array}{l}\text { teuer } \\
\text { mäßig toxisch } \\
\text { mögliche systemische NW: } \\
\text { Eisenmangel, allergische } \\
\text { Reaktionen }\end{array}$ \\
\hline Cholin-Tetrathiomolybdat & $\begin{array}{l}\text { Bildung eines Kupfer- } \\
\text { Protein-Thiomolybdat } \\
\text { komplexes, der nicht } \\
\text { resorbiert wird }\end{array}$ & $\begin{array}{l}\text { Empfehlungen zur Dosie- } \\
\text { rung liegen noch nicht vor } \\
\text { (Ergebnisse der Phase-III- } \\
\text { Studie werden } 2021 \text { er- } \\
\text { wartet) }\end{array}$ & $\begin{array}{l}\text { schneller Wirkungseintritt } \\
\text { wenige Nebenwirkungen }\end{array}$ & $\begin{array}{l}\text { keine Langzeiterfahrungen } \\
\text { aktuell nicht zugelassen, } \\
\text { klinische Studien laufen } \\
\text { noch }\end{array}$ \\
\hline $\begin{array}{l}\text { Zinksalze (Zinkazetat, } \\
\text {-sulfat, -histidin) }\end{array}$ & $\begin{array}{l}\text { Metallothionein-Induktion } \\
\text { in Enterozyten } \\
\text { Verminderung der } \\
\text { Kupferresorption }\end{array}$ & $\begin{array}{l}3 \times 25-50 \text { mg getrennt } \\
\text { von den Mahlzeiten } \\
\text { Beginn mit Gesamtdosis } \\
\text { möglich }\end{array}$ & nicht toxisch & $\begin{array}{l}\text { langsamer Wirkungs- } \\
\text { eintritt } \\
\text { gastrointestinale } \\
\text { Unverträglichkeit }\end{array}$ \\
\hline
\end{tabular}

Sowohl für D-Penicillamin als auch für die beiden verfügbaren Trientine-Präparate (Trientine-dihydrochlorid und Trientine-tetrahydrochlorid) gilt, dass insbesondere die Ein- und Aufdosierung langsam erfolgen muss, um toxische Nebenwirkungen und/oder Unverträglichkeitsreaktionen zu vermeiden. Gefürchtet ist in diesem Zusammenhang unter D-Penicillamin, seltener auch unter Trientine, vor allem eine Verschlechterung des neurologischen Befundes bis hin zu schwerwiegenden irreversiblen Schäden. Der Mechanismus ist letztlich nicht geklärt, direkte toxische Effekte in Verbindung mit der Toxizität durch freies Kupfer werden als mögliche Ursache diskutiert.

Ist eine Therapie mit einem Chelator indiziert, ist D-Penicillamin noch immer das Mittel der 1. Wahl. Sowohl Trientine-dihydrochlorid als auch Trientine-tetrahydrochlorid kommen laut Zulassung vorerst nur dann zum Einsatz, wenn D-Penicillamin kontraindiziert ist, es zu unerwünschten Nebenwirkungen während der Behandlung mit D-Penicillamin kommt oder die Therapie nicht effektiv ist. Eine Kombination verschiedener Chelatoren kann nicht empfohlen werden. Die Kombination eines Chelators (renale Eliminierung des Kupfers) und eines Zinksalzes (Reduktion der enteralen Kupferresorption) wäre theoretisch eine gute Option, praktisch ließe sich das für die meisten Patientinnen und Patienten aufgrund der Einnahmemodalitäten mit ausrei- chendem Abstand der Medikation zu den Mahlzeiten und der Medikamente zueinander nicht umsetzen.

Perspektivisch steht mit Tetrathiomolybdat ein weiterer Chelatbildner zur Verfügung. Die Substanz wurde erstmals von Walshe [27] empfohlen und im Nachgang umfassend von Brewer [28] untersucht und eingesetzt. Aufgrund angenommener geringerer Toxizität ist diese Substanz möglicherweise gut zur Initialtherapie bei neurologischer Manifestation geeignet. Ergebnisse einer Phase-II-Studie wurden im Dezember 2017 veröffentlicht, danach erwies sich Cholintetrathiomolybdat als wirksam und sicher [29]. Die Ergebnisse der PhaseIII-Studie werden 2021 erwartet.

Durch Bildung eines nierengängigen Kupferchelatkomplexes mobilisieren Chelatbildner die Kupferdepots. Im Gegensatz dazu induzieren Zinksalze die Metallothioneinsynthese in den Enterozyten, sodass Kupfer vermehrt an Metallothionein gebunden und als Kupfermetallothioneinkomplex mit dem Stuhl ausgeschieden werden kann $[28,29]$. 
In $>$ Tab. 5 (modifiziert nach [8]) sind die derzeit verfügbaren bzw. in Studien untersuchten Substanzen, ihr Wirkmechanismus, empfohlene Dosierungen sowie ihre wesentlichen Vor- und Nachteile zusammengefasst.

\section{Merke}

Mit Trientine-dihydrochlorid (200 mg Wirkstoff) und Trientine-tetrahydrochlorid (150 mg Wirkstoff)

stehen zwei unterschiedliche Trientinepräparate zur Verfügung, eine 1:1 Umstellung ist nicht möglich!

Obwohl der Schwerpunkt auf der spezifischen medikamentösen („entkupfernden“) Therapie liegt, kann es erforderlich sein, dass passager oder dauerhaft symptomatisch medikamentös behandelt werden muss. Welche Substanzen, in welcher Dosierung und für welche Dauer eingesetzt werden, richtet sich nach der Zielsymptomatik unter Berücksichtigung eines ausgewogenen Nutzen-Nebenwirkungs-Profils. Häufig eingesetzt werden neben L-Dopa-Präparaten Clonazepam aus der Gruppe der Benzodiazepine, Tiaprid, obwohl selbst zur Gruppe der Neuroleptika gehörend als „Antihyperkinetikum“, ferner auch Antidepressiva, (atypische) Antipsychotika und Botulinumtoxin.

Wie für die spezifische Therapie gilt auch hier, dass mit zunehmender Verbesserung der Kupferbilanz in der Regel auch die jeweilige Zielsymptomatik rückläufig ist und von daher regelmäßige Therapiekontrollen und -anpassungen geboten sind. Weitere wesentliche Säulen der Behandlung sind Physio-, Ergo- und Logopädie sowie die Verordnung von Hilfsmitteln und die Einleitung sozialmedizinischer Maßnahmen (Schwerbehindertenausweis, Pflegegrad etc.).

\section{Lebertransplantation}

Eine Lebertransplantation ist nur selten und nur im Falle eines fulminanten Leberversagens indiziert. Da die Lebertransplantation den genetischen Defekt in der Leber korrigiert, ist keine weitere entkupfernde Therapie erforderlich. Die Langzeitprognose nach Transplantation ist in aller Regel günstig [6].

\section{Therapiekontrolle}

\section{Merke \\ Symptomfreiheit und Erreichen einer ausgeglichenen Kupferbilanz sind die Ziele der Therapie. Wichtigster paraklinischer Zielparameter ist dabei die Kupferaus- scheidung im Urin.}

Gemessen wird die Kupferausscheidung im Urin im 24h-Sammelurin unter Therapie und nach einer definierten Therapiepause von 2 (-3) Tagen (je nach Zentrum). Die Therapie gilt als erfolgreich, wenn die basale Kupferausscheidung normal ist und darüber hinaus keine

\section{FALLBEISPIEL}

\section{Fall 4: Fulminantes Leberversagen}

Im 21. Lebensjahr Vorstellung aufgrund eines grobschlägigen Tremors beider Hände/Arme in Form eines Halte- und Aktionstremors. Positive Familienanamnese für essenziellen Tremor.

Im Rahmen der differenzialdiagnostischen Abklärung laborchemische Konstellation wie bei Morbus Wilson, Laborabweichungen allerdings nur geringfügig. Retrospektiv in der Kindheit anamnestisch Hepatitis.

Diagnosesicherung Morbus Wilson, monosymptomatisch, nach D-Penicillamin-Belastungstest und Radiokupfertest. Therapie mit D-Penicillamin und Pyridoxinhydrochlorid, nach Monaten klinisch asymptomatisch mit normaler Kupferbilanz im 24-h-Sammelurin. Bei sehr guter Compliance Symptomfreiheit über Jahre.

Akutvorstellung mit klinischen Zeichen der Leberdekompensation, Schwangerschaft im 5. Monat. Ohne Absprache hatte die Patientin aus Sorge vor möglicher Schädigung des Fetus durch D-Penicillamin die Therapie abgebrochen. Eine Rekompensation bzw. Stabilisierung zur Lebertransplantation gelang nicht, die Patientin verstarb im fulminanten Leberversagen.

- Tab.6 Empfohlene Zielparameter der Kupferausscheidung im 24-StundenSammelurin während der Erhaltungsphase entsprechend der DGN-Leitlinie.

\begin{tabular}{|l|l|l|l|}
\hline $\begin{array}{l}\text { Kupferausscheidung } \\
\text { im 24-Stunden- } \\
\text { Sammelurin mit } \\
\text { Medikation }\end{array}$ & D-Penicillamin & Trientine & Zink \\
\hline DGN-Leitlinie & & & \\
& & & \\
& $\begin{array}{l}>500 \mu \mathrm{g} / 24 \mathrm{~h} \\
(>7,5 \mu \mathrm{mol} /\end{array}$ & $\begin{array}{l}>200 \mu \mathrm{g} / 24 \mathrm{~h} \\
(>7,5 \mu \mathrm{mol} /\end{array}$ & $\begin{array}{l}<80 \mu \mathrm{g} / 24 \mathrm{~h} \\
(<1,0 \mu \mathrm{mol} /\end{array}$ \\
& $24 \mathrm{~h})$ & $24 \mathrm{~h})$ & $24 \mathrm{~h})$ \\
\hline
\end{tabular}

wesentlichen Abweichungen des Blutbildes und der Leberfunktionsparameter vorliegen. In > Tab. 6 sind die empfohlenen Zielparameter der Kupferausscheidung im 24-h-Sammelurin während der Erhaltungsphase entsprechend der DGN-Leitlinie dargestellt.

Neben der Überprüfung der Kupferausscheidung im Sammelurin sollten darüber hinaus Kontrollen des Blutbildes, der Leber- und Nierenfunktionsparameter sowie des Eisenstoffwechsels erfolgen, insbesondere auch, um mögliche unerwünschte Effekte der Therapie frühzeitig zu erfassen. Weitere wichtige Kontrollparameter sind die Serumspiegel für Kupfer und Zink und die Analyse des Urins (Hinweis auf Proteinurie). Sollte eine Leberzirrhose vorliegen, kann die Bestimmung des AlphaFetoproteins helfen, ein hepatozelluläres Karzinom zu identifizieren. Ferner sollten Knochenstoffwechselparameter und die DXA-Messung in großen Abständen in die Kontrollen einbezogen werden. 


\section{FALLBEISPIEL}

\section{Fall 5: Rezidiv nach Therapiepause}

Im 26. Lebensjahr im Rahmen einer Routineuntersuchung Zufallsbefund eines Kayser-Fleischer-Kornealrings. Die weitere Diagnostik erfolgte mit erheblicher zeitlicher Verzögerung, sodass sich zwischenzeitlich ein hypokinetisch rigides Syndrom manifestierte. Unter Therapie mit D-Penicillamin und Pyridoxinhydrochlorid über 2 Jahre „Entkupferung“. Nachfolgend für ca. 8 Jahre klinisch asymptomatisch, normale Kupferbilanz im 24-h Sammelurin. Im 34. Lebensjahr Diagnose eines Kupfermangels, deshalb Reduktion der Chelatortherapie und schließlich (auf ärztliches Anraten) komplettes Pausieren der Therapie für 6 Monate. Während der Therapiepause Entwicklung eines schweren hypokine- tisch-rigiden Syndroms - klinisch dem Vollbild eines Parkinson-Syndroms vom Äquivalenztyp entsprechend. Darüber hinaus schwere depressive Episode mit Stimmungs- und Antriebstief sowie gestörtem Biorhythmus.

Vorsichtige Wiedereindosierung von D-Penicillamin und Pyridoxinhydrochlorid mit guter Verträglichkeit. Nach ca. 21/2 Jahren gute klinische Rekompensation ohne Beeinträchtigung der Alltagskompetenzen. Residuell verblieben sind jedoch eine rasche psychophysische Erschöpfbarkeit, eine Minderung der Belastbarkeit mit reduziertem Leistungsspannungsbogen, ein leichtgradig gebundenes Gangbild und unter Stress irreguläre dystone Verkrampfungen einzelner Finger.

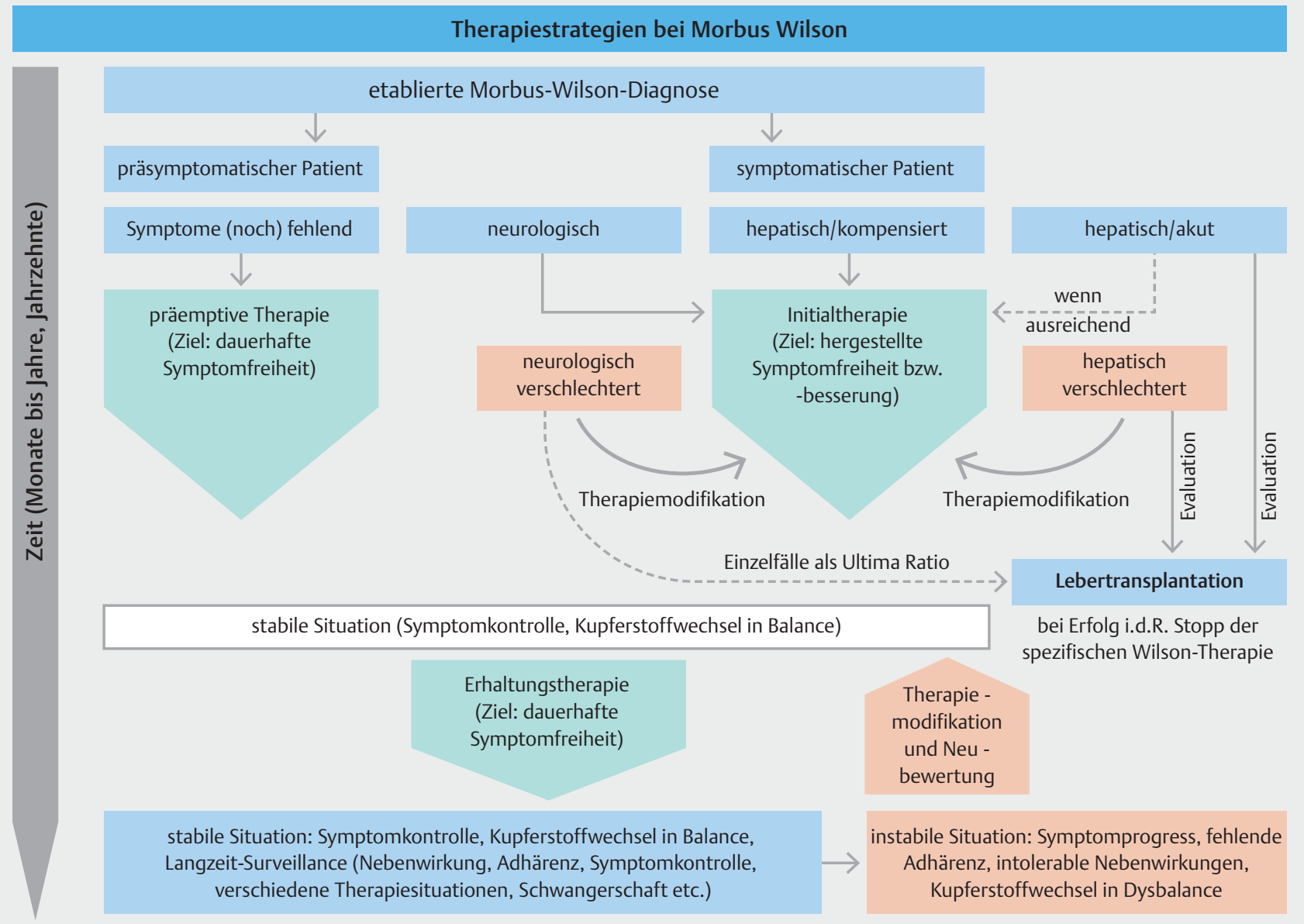

Abb.7 Therapiestrategien bei Morbus Wilson (Quelle: Reuner U, Huster D. Therapie des Morbus Wilson. In: Höglinger GU, Hrsg. ParkinsonSyndrome kompakt, Diagnostik und Therapie in Klinik und Praxis. Stuttgart: Thieme; 2019). 
Obwohl in der Praxis immer wieder diskutiert, gibt es bisher keine verbindliche Definition für eine „Übertherapie“. Welche Laborparameter und welche konkreten Grenzwerte sich zur Kontrolle eignen, ist bisher nicht geklärt. Im klinischen Alltag stellt sich jedoch oft die Frage, wie niedrig die Serumkupferwerte unter Therapie sein dürfen, ohne dass es zu einem relevanten Aktivitätsverlust der kupferabhängigen mitochondrialen Cytochrom C-Oxidase (COX) und somit über eine mitochondriale Schädigung zu einer Myeloneuropathie kommen kann. In der Literatur wurde darüber bisher nur kasuistisch berichtet [30].

Wie die Therapie selbst ist auch ihr Monitoring individuell und variabel. Während in der Phase der Initialtherapie die Kontrollintervalle in Abhängigkeit von klinischen und paraklinischen Befunden sowie von der Verträglichkeit der Therapie engmaschig sein müssen/ können, sollten sie in der Erhaltungsphase 3-6 Monate nicht überschreiten. Für neurologisch manifeste Patienten sollten bildgebende und elektrophysiologische Untersuchungen zu Beginn der Therapie und im Verlauf nach 2 - 4 (6) Jahren erfolgen, bei vermutetem Therapieversagen entsprechend eher.

Ein vielversprechender Biomarker zum Monitoring neurologisch manifester Patienten könnte in Zukunft das Neurofilament (Nfl) im Plasma sein. Shribmann und Mitarbeiter konnten erst kürzlich zeigen, dass das Neurofilament im Plasma bei „neurologisch aktiver Erkrankung“ mit dem Ausmaß der klinisch-neurologischen Manifestation korreliert und höher als bei hepatisch Betroffenen ist [31].

Die Therapiestrategien bei Morbus Wilson fasst $>$ Abb. 7 zusammen.

Merke

Für eine dauerhaft erfolgreiche Therapie ist neben einer sorgfältigen Überwachung und Anpassung der Therapie im Langzeitverlauf letztlich die Motivation und „Therapietreue“ der Patienten entscheidend.

\section{KERNAUSSAGEN}

- Der Morbus Wilson ist eine seltene autosomal-rezessiv vererbte Multisystemerkrankung, der eine Störung des hepatischen Kupferstoffwechsels zugrunde liegt.

- Frühzeitig erkannt und behandelt ist die Prognose in der Regel günstig, Symptomfreiheit und normale Lebenserwartung sind realistische Therapieziele.

- Grundsätzlich werden eine überwiegend hepatische und eine überwiegend neurologische Verlaufsform unterschieden, selten sind rein psychiatrische Erstmanifestationen möglich. Häufig finden sich Mischformen.

- Entscheidend für die Diagnosestellung ist, den Morbus Wilson überhaupt in die differenzialdiagnostischen Überlegungen einzubeziehen. Die Diagnose ist dann relativ einfach nach einem Stufenschema zu stellen:

- Anamnese;

- allgemein-klinischer, klinisch-neurologischer und psychischer Befund;

- Labordiagnostik, insbesondere Untersuchung der Kupferstoffwechselparameter;

- Untersuchung an der Spaltlampe;

- zerebrale Bildgebung mittels MRT;

- molekulargenetische Diagnostik.

- Da eine kausale Therapie nicht möglich ist, besteht das Behandlungsziel im Erreichen einer normalen Kupferhomöostase durch Erhöhung der renalen Kupferelimination und/oder Reduktion der enteralen Kupferresorption. Verschiedene Substanzen mit unterschiedlichen Wirkmechanismen stehen dazu zur Verfügung.

- Chelatbildner mobilisieren die Kupferdepots durch Bildung eines nierengängigen Kupferchelatkomplexes, wohingegen Zinksalze die Metallothioneinsynthese in den Enterozyten induziert, sodass Kupfer vermehrt an Metallothionein gebunden und als Kupfermetallothioneinkomplex mit dem Stuhl ausgeschieden wird.

- Die Therapie muss lebenslang erfolgen, sie darf nie für einen längeren Zeitraum unterbrochen werden, da sonst eine erneute Kupferakkumulation und damit einhergehend klinische Verschlechterungen drohen.

- Schwangerschaft und Stillperiode gelten als sicher, sofern die Therapie konsequent fortgeführt und gut monitoriert wird. Stillen wird zwar nicht empfohlen, im klinischen Alltag aber häufig „erlaubt“, ohne dass bislang über Probleme berichtet wurde. 


\section{Interessenkonflikt}

Erklärung zu finanziellen Interessen

Forschungsförderung erhalten: nein; Honorar/geldwerten Vorteil für Referententätigkeit erhalten: ja von einer anderen Institution; Bezahlter Berater/interner Schulungsreferent/Gehaltsempfänger: ja von einer anderen Institution; Patent/Geschäftsanteile/Aktien (Autor/Partner, Ehepartner, Kinder) an Firma (Nicht-Sponsor der Veranstaltung): nein; Patent/Geschäftsanteile/Aktien (Autor/Partner, Ehepartner, Kinder) an Firma (Sponsor der Veranstaltung): nein.

Erklärung zu nichtfinanziellen Interessen

Die Autorinnen/Autoren geben an, dass kein Interessenkonflikt besteht.

\section{Autorinnen/Autoren}

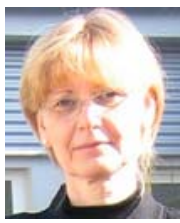

\section{Ulrike Reuner}

Dr. med., Fachärztin für Neurologie und Psychiatrie/Psychotherapie. Seit 1991 als Oberärztin an der Klinik und Poliklinik für Neurologie am Universitätsklinikum Dresden in verschiedenen Abteilungen tätig. Interessensschwerpunkte: „seltene Erkrankungen“ wie Morbus Wilson und neuromuskuläre Erkrankungen, Genetik (fachgebundene Zusatzqualifikation) und Palliativmedizin (Zusatzbezeichnung). Leiterin der Spezialambulanz Morbus Wilson. Langjährige Mitarbeit u.a. im Komitee für klinische Ethikberatung am UKD und der Sächsischen Landesärztekammer. Gastdozentin an der DIU - Dresden International University und der Akademie für Palliativmedizin und Hospizarbeit Dresden.

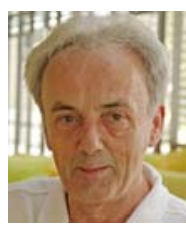

\section{Jürgen Dinger}

PD Dr.med. habil., Facharzt für Kinder- und Jugendmedizin, Subspezialisierung Neonatologie und pädiatrische Intensivmedizin. Seit 1996 als Oberarzt an der Klinik und Poliklinik für Kinder- und Jugendmedizin am Universitätsklinikum Dresden tätig. Seit 2007 Leitender Oberarzt des Fachbereiches Neonatologie und Pädiatrische Intensivmedizin. Interessensschwerpunkte: Beatmung, „seltene Erkrankungen“ und deren Risiken für Mutter und Neugeborenes, Genetik (fachgebundene Zusatzqualifikation), Palliativmedizin. Langjährige Mitarbeit im Komitee für klinische Ethikberatung am Universitätsklinikum. Gastdozent an der DIU - Dresden International University.

\section{Korrespondenzadresse}

\section{Dr. med. Ulrike Reuner}

Klinik und Poliklinik für Neurologie Universitätsklinikum Carl Gustav Carus

Technische Universität Dresden

Fetscherstraße 74, 01307 Dresden

Ulrike.Reuner@uniklinikum-dresden.de
Wissenschaftlich verantwortlich gemäß Zertifizierungsbestimmungen

Wissenschaftlich verantwortlich gemäß Zertifizierungsbestimmungen für diesen Beitrag ist Dr. med. Ulrike Reuner, Dresden.

\section{Literatur}

[1] AWMF. Leitlinien für Diagnostik und Therapie in der Neurologie. Morbus Wilson, Registriernummer 030/91. Im Internet (Stand 11.01.2021): https://www.awmf.org/leitlinien/ detail/II/030-091.html

[2] Wilson SAK. Progressive lenticular degeneration: a familial nervous disease associated with cirrhosis of the liver. Brain 1912; 34: 295-507

[3] Bandmann O, Weiss KH, Kluge R et al. Wilson's disease and other neurological copper disorders. Lancet Neurol 2015; 14: $103-113$

[4] Kim JW, Kim JH, Seo JK et al. Genetically confirmed Wilson disease in a 9-month old boy with elevations of aminotransferases. World J Hepatol 2013; 5: 156-159

[5] Ala A, Borjigin J, Rochwarger A et al. Wilson disease in septuagenarian siblings: raising the bar for diagnosis. Hepatology 2005; 41: 668-670

[6] Huster D. Morbus Wilson. Internist 2018; 59: 159-174

[7] Hermann W. Morbus Wilson. In: Diener H-C, Steinmetz H, Kastrup O. Referenz Neurologie, Kap 25.244 Stuttgart: Thieme; 2019: 9783132413870

[8] Reuner U, Huster D. Therapie des Morbus Wilson. In: Höglinger GU. Parkinson-Syndrome kompakt, Diagnostik und Therapie in Klinik und Praxis. Stuttgart: Thieme; 2019

[9] Leinweber B, Möller JC, Scherag A et al. Evaluation of the Unified Wilson's disease rating scale (UWDRS) in German patients with treated Wilson's disease. Mov Disorders 2008; $23: 54-62$

[10] Hermann W, Huster D. Diagnostik des Morbus Wilson. Nervenarzt 2018; 89: 115-123

[11] Hefter H, Arendt G, Stremmel W et al. Motor impairment in Wilson's disease, slowness of voluntary limb movements. Acta Neurol Scand 1993; 87: 133-147

[12] Thomas L. Labor und Diagnose. Frankfurt/Main: TH-Books; 1998

[13] El Balkhi S et al. Relative exchangeable copper: A highly sensitive and highly specific biomarker for Wilson's disease diagnosis. Clin Chim Acta 2011; 412: 2254-2260

[14] Trocello JM et al. Relative exchangeable copper: A promising tool for family screening in Wilson's disease. Mov Disorders 2014; 29: 558-562

[15] Coffey AJ, Durkie M, Hague $S$ et al. A genetic study of Wilson's disease in the United Kingdom. Brain 2013; 136: 1476-1487

[16] Mahlknecht P, Schocke M, Seppi K. Differentialdiagnose der Parkinson-Syndrome mittels MRT. Nervenarzt 2010; 81: 1168-1179

[17] Schlaug G, Hefter H, Engelbrecht V et al. Neurological impairment and recovery in Wilson's disease: evidence from PET and MRI. J Neurol Sci 1996; 136: 129-139

[18] Czlonkowska A, Litwin T, Chabik G. Wilson disease: Neurologic features. In: Aminhoff M], Boller F, Swaab DF. Hand- 
book of clinical neurology, vol. 142. Amsterdam: Elsevier; 2017: 101-119

[19] Karlas T, Hempel M, Troltzsch M et al. Non-invasive evaluation of hepatic manifestation in Wilson disease with transient elastography, ARFI, and different fibrosis scores. Scand J Gastroenterol 2012; 47: 1353-1361

[20] Ferenci P, Caca K, Loudianos G et al. Diagnosis and phenotypic classification of Wilson disease. Liver Int 2003; 23: 139-142

[21] Pfeiffenberger ], Beinhardt s, Gotthardt DN et al. Pregnancy in Wilson's disease: management and outcome. Hepatology 2018; 67: 1261-1269

[22] Reuner U, Dinger J. Pregnancy and Wilson disease: management and outcome of mother and newborns-experiences of a perinatal centre. Ann Transl Med 2019; 7 : (Suppl. 02): S56-S60doi:10.21037/atm.2019.04.40

[23] Ferenci P, Czlonkowska A, Stremmel W et al. EASL clinical practice guidelines: Wilson's disease. J Hepatol 2012; 56: 671-685

[24] Diener HC, Weimar C. Leitlkinien für Diagnostik und Therapie in der Neurologie, Herausgegeben von der Kommission "Leitlinien“ der Deutschen Gesellschaft für Neurologie. Kap. 14: Morbus Wilson. Stuttgart: Thieme; 2012

[25] Roberts EA, Schilsky ML. Diagnosis and treatment of Wilson disease: an update. Hepatology 2008; 47: 2089-2111

[26] Socha P, Janczyk W, Dhawan A et al. Wilson's Disease in children: a position paper by the Hepatology Committee of the European Society for Paediatriv Gastroenterology, Hepatology and Nutrition. JPGN 2018; 66: 334-344
[27] Walshe JM. Penicillamine, a new oral therapy for Wilson's disease. Am J Med 1956; 21: 487-495

[28] Brewer G]. The modern treatment of Wilson's disease. J Gastrintest Dig Syst 2015; 5: 312

[29] Weiss KH, Askari FK, Czlonkowska A et al. Bis-choline tetrathiomolybdat in oatients with Wilson's disease: an openlabel, multicentre phase 2 study. Lancet Gastroenterol Hepatol 2017; 12: 869-876

[30] da Silva-Junior FP, Machado AAC, Lucato LT et al. Copper deficiency myeloneuropathy in a patient with Wilson disease. Neurology 2011; 76: 1673-1674

[31] Shribman S, Heller C, Burrows M et al. Plasma neurofilament light as a biomarker of neurological involvement in Wilson's disease. movement disorders 2020. Wiley Online Library; Im Internet (Stand 11.01.2021): doi:10.1002/ mds.28333https://onlinelibrary.wiley.com/doi/full/ 10.1002 /mds. 28333

Bibliografie

Neurologie up2date 2021; 4: 71-89

DOI $10.1055 / \mathrm{a}-0956-2573$

ISSN 2511-3453

(c) 2021. Thieme. All rights reserved.

(c) Georg Thieme Verlag KG Stuttgart · New York 


\section{Punkte sammeln auf CME.thieme.de}

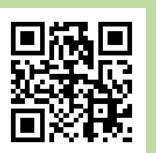

Diese Fortbildungseinheit ist in der Regel 12 Monate online für die Teilnahme verfügbar.

Den genauen Einsendeschluss finden Sie unter https://cme.thieme.de/CXDFC69.

Sollten Sie Fragen zur Online-Teilnahme haben, finden Sie unter https://cme.thieme.de/hilfe

eine ausführliche Anleitung. Wir wünschen viel Erfolg beim Beantworten

der Fragen!

Unter https://eref.thieme.de/CXDFC69 oder über den QR-Code kommen Sie direkt zur Startseite des Wissenstests.

VNR 2760512021160211268

\section{Frage 1}

Aufgrund welcher Laborkonstellation besteht der Verdacht auf einen Morbus Wilson?

A Kupfer im Serum erhöht, Coeruloplasmin im Serum erhöht, Urinkupfer erniedrigt

B Kupfer im Serum erhöht, Coeruloplasmin im Serum normal, Urinkupfer erniedrigt

C Kupfer im Serum erniedrigt, Coeruloplasmin im Serum erhöht, Urinkupfer normal

D Kupfer im Serum erniedrigt, Coeruloplasmin im Serum erniedrigt, Urinkupfer erhöht

E Kupfer im Serum erhöht, Coeruloplasmin im Serum erhöht, Urinkupfer erhöht

\section{Frage 2}

Welches ist das typische Manifestationsalter für die neurologische Verlaufsform des Morbus Wilson?

A In der Kindheit, vorzugsweise zwischen dem 4. und 10. Lebensjahr.

B Nach der Pubertät und im jungen Erwachsenenalter, zwischen dem 15. und 30. Lebensjahr.

C Im Erwachsenenalter, zwischen dem 40. und 50. Lebensjahr.

D Immer jenseits des 60. Lebensjahres.

E Es gibt kein bevorzugtes Lebensalter.

\section{Frage 3}

Welche Aussage zu Symptomen und Befunden trifft zu?

A Tremor und Feinmotorikstörungen sind mögliche Frühsymptome einer neurologischen Manifestation.

B Hirnstammanfälle und Spastik sind häufige Symptome des Morbus Wilson.

C Neurologische und psychiatrische Manifestationen treten gleich häufig auf.

D Fehlt der Kayser-Fleischer-Korneal-Ring, muss an der Diagnose Morbus Wilson gezweifelt werden.

E Normale Leberwerte schließen einen Morbus Wilson aus.

\section{Frage 4}

Welche Aussage zu Zusatzbefunden bei V.a. Morbus Wilson trifft nicht zu?

A Der Kayser-Fleischer Kornealring gilt als pathognomonisch für einen Morbus Wilson.

B Unbehandelte neurologisch manifeste Patienten weisen immer bildmorphologische Veränderungen im SchädelMRT auf.

C Ein vor Therapie verminderter Glukosemetabolismus in der 18 FDG-Hirn-PET kann sich unter Therapie vollständig erholen.

D Zur Sicherung der Diagnose Morbus Wilson ist die Leberbiopsie obligat.

E Die Abdomensonografie und die Leberelastizitätsmessung - meistens kombiniert durchgeführt - besitzen einen hohen diagnostischen Stellenwert.

\section{Frage 5}

Eine der folgenden Aussagen zum Leipzig Score trifft nicht zu. Welche?

A Der Leipzig Score wurde 2001 von einem Expertengremium entwickelt und im Verlauf validiert.

B Der Leipzig Score bewertet klinische und paraklinische Befunde.

C Eine Schwäche des Leipzig Scores ist, dass er psychopathologische Befunde nicht erfasst.

D 4 Punkte im Leipzig Score sichern die Diagnose bzw. machen sie hochwahrscheinlich.

E Ein Vorteil des Leipzig Scores ist, dass mit dem Nachweis zweier Mutationen im Wilson-Gen die Diagnose gesichert werden kann, weitere Befunde sind nicht notwendig. 


\section{Punkte sammeln auf CME.thieme.de}

Fortsetzung ...

\section{Frage 6}

Welcher cMRT-Befund ist gut mit der Diagnose eines Morbus Wilson vereinbar?
A das Kolibrizeichen
B das Hot-Cross-Bun-Zeichen
C das Pandabär-Zeichen
D das Tigeraugenzeichen
E eine halbseitige Hirnatrophie

\section{Frage 7}

Welche Aussage zur Genetik trifft zu?

A Der Morbus Wilson wird autosomal-dominant vererbt, der Genort befindet sich auf dem kurzen Arm von Chromosom 13.

B Der Morbus Wilson wird autosomal-rezessiv vererbt, der Genort befindet sich auf dem langen Arm von Chromosom 13.

C Geschwister Betroffener sind nur zu untersuchen, wenn sie erste Symptome aufweisen, da eine präemptive Therapie nicht üblich ist.

D Bisher sind ca. 200 Mutationen bekannt.

E Männer erkranken häufiger als Frauen, das Verhältnis beträgt 2:1.

\section{Frage 8}

Eine der folgenden Aussagen zur Therapie des Morbus Wilson trifft nicht zu. Welche?

A Zur Erhöhung der Kupferausscheidung durch Chelatbildung stehen D-Penicillamin und zwei Trientine-Präparate zur Verfügung.

B Tetrathiomolybdat soll bei neurologischer Manifestation besonders günstig wirken, in Deutschland ist es noch nicht zur Therapie zugelassen.

C Zinksalze verhindern die intestinale Resorption von Kupfer.

D Chelatbildner und Zinksalze sollten nicht zeitgleich eingenommen werden.

E Nach erfolgreicher Entkupferung ist eine lebenslange kupferarme Diät ausreichend, eine medikamentöse Therapie ist dann nicht mehr erforderlich.

\section{Frage 9}

Welche Aussage zur Therapie während einer Schwangerschaft und Stillperiode trifft nicht zu?

A Die Dosis der Chelatbildner sollte so gering wie möglich, aber ausreichend sein.

B Idealerweise sollte die Entkupferung vor Eintritt einer Schwangerschaft abgeschlossen sein.

C Sowohl die Therapie mit Chelatbildnern als auch mit Zinksalzen wird in der Regel von Mutter und Kind gut vertragen.

D Während einer Schwangerschaft muss die Wilson-spezifische Therapie jedenfalls fortgesetzt werden.

E Aufgrund zahlreicher Daten aus systematischen Reviews darf die Wilson-spezifische Therapie während der Stillzeit nicht eingenommen werden.

\section{Frage 10}

Welche Aussage zum Verlauf und zur Prognose trifft nicht zu?

A Die Therapie ist lebenslang notwendig.

B Eine Besserung manifester Symptomatik ist etwa bis zu 2 Jahren nach Therapiebeginn möglich.

C Der Therapieerfolg ist vom Genotyp abhängig, eine Genotyp-Phänotyp-Korrelation gilt als gesichert.

D Sofern rechtzeitig erkannt und behandelt, ist die Prognose der Erkrankung in der Regel gut, sowohl in Bezug auf die Lebensqualität als auch auf die Lebenserwartung.

E Unbehandelt verläuft die Erkrankung über ein chronisches Stadium innerhalb von Jahren tödlich. 